ISSN 0103-8478

\title{
Épocas de emergência de Brachiaria brizantha no desenvolvimento da cultura da soja
}

\author{
Brachiaria brizantha emergence periods on soybean development
}

\author{
Andréia Cristina Silva ${ }^{1}$ Lino Roberto Ferreira ${ }^{2}$ Antônio Alberto da Silva ${ }^{2}$ \\ Rogério Soares Freitas $^{3}$ Allan Mauro ${ }^{4}$
}

\section{RESUMO}

A integração agricultura-pecuária beneficia simultaneamente a produção de grãos e a pecuária. Todavia, a forrageira tem sido a principal espécie daninha que compete com a cultura anual. Objetivou-se, neste trabalho, quantificar os efeitos de épocas de emergência de Brachiaria brizantha em relação à cultura da soja. O experimento foi realizado em casa de vegetação, avaliando-se sete épocas de emergência de B. brizantha em relação à cultura da soja $(-21,-14,-7,0$, 7, 14 e 21 dias da emergência da soja) e da soja em monocultivo. No estádio R2 da soja, foram determinados o número de colmos de $\boldsymbol{B}$. brizantha, a área foliar e a partição de biomassa seca de ambas as espécies e o número de folhas trifolioladas e de nós de soja. No estádio R8 da soja, foram avaliados a biomassa seca total da parte aérea e o número de colmos da forrageira, assim como a produção de grãos por planta e o número de vagens por planta e de sementes por vagem da soja. A época de emergência da B. brizantha em relação à da soja foi determinante no crescimento de ambas as espécies. Foi observada redução da produção de grãos por planta de soja consorciada, comparada ao monocultivo, de aproximadamente 97, 96, 91, 80, 34, 27 e $15 \%$ quando $B$. brizantha emergiu aos $-21,-14,-7,0,7,14$ e 21 dias da emergência da soja, respectivamente, sendo o acúmulo de biomassa seca da parte aérea da forrageira nos respectivos tratamentos de 275, 279, 267, 202, 79, 46 e 23 gramas por vaso. Em ordem decrescente, a suscetibilidade das características morfológicas da soja, avaliadas no estádio $R 2$, devido à interferência imposta por B. brizantha ocorreu da seguinte maneira: número de folhas trifolioladas e área foliar > biomassa seca de folhas, haste, raízes e nódulos > número de nós. O número de vagens por planta da soja consorciada foi semelhante ao do monocultivo quando $\mathbf{B}$. brizantha emergiu aos 21 dias da emergência da soja, e o de sementes por vagem somente foi reduzido quando esta espécie emergiu a -21 e-14 dias da emergência da soja.

Palavras-chave: Glycine max, braquiária, competição, interferência, partição de biomassa.

\section{ABSTRACT}

Crop-livestock integration benefits grain and animal production simultaneously. However, the weed species that mainly competes with the annual crop is forage. This study aimed at the quantification of Brachiaria brizantha emergence periods on soybean. The trial carried out under greenhouse conditions evaluated 7 emergence periods of $\boldsymbol{B}$. brizantha $(-21,-14,-7,0$, 7,14 , and 21 days after soybean emergence) and soybean monocrop. When soybean was in full flower (stage R2), the leaf area and dry biomass partitioning in both species, the number of trifoliolate leaves and nodes per soybean plant, as well as the stem number of $\boldsymbol{B}$. brizantha were evaluated. At soybean harvest (stage R8) the aerial dry biomass and stem number of B. brizantha were determined as well as the grain yield per plant, number of pods per plant, and number of seeds per pod. The B. brizantha emergence period in relation to soybean was determinant for both species'growth. A grain yield reduction for intercropped soybean compared to soybean monocrop of $97,96,91,80,34,27$, and $15 \%$ was observed, approximately, when $B$. brizantha emerged within -21, -14, -7, 0, 7, 14, and 21 days, respectively. The forage accumulated an aerial dry biomass of 275, 279, 267, 202, 79, 46, and $23 \mathrm{~g}$ per pot in these treatments, respectively. Listed in decreasing order, the morphological traits expressing soybean susceptibility to $\boldsymbol{B}$. brizantha interference were: trifoliolate leaf numbers and leaf area $>$ dry biomass of leaves, stem, roots and nodules $>$ node number. The number of pods per soybean plant

\footnotetext{
${ }^{1}$ Engenheiro Agrônomo, Mestre em Produção Vegetal, Doutoranda em Fitotecnia, Universidade Federal de Viçosa (UFV), 36571-000, Viçosa, MG, Brasil. E-mail: andreia@vicosa.ufv.br. Autor para correspondência.

${ }^{2}$ Engenheiro Agrônomo, Doutor, Professor Adjunto do Departamento de Fitotecnia da UFV, Viçosa, MG, Brasil.

${ }^{3}$ Engenheiro Agrônomo, Mestre em Fitotecnia, Doutorando em Fitotecnia, UFV, Viçosa, MG, Brasil.

${ }^{4}$ Graduando do Curso de Agronomia da UFV, Viçosa, MG, Brasil.
} 
was not affected by $\boldsymbol{B}$. brizantha interference when its emergence occurred 21 days after soybean emergence and the number of seeds per pod was only negatively affected when the forage emergence occurred -21 and -14 days after soybean's.

Key words: Glycine max, Brachiaria, competition, interference, biomass partitioning.

\section{INTRODUÇÃO}

O cultivo da soja tem sido uma das principais alternativas para a recuperação e renovação de pastagens degradadas, e a rotação da soja com pastagem (dois a três anos) tem propiciado benefícios para ambas as culturas (KICHEL et al., 2000). A espécie Brachiaria brizantha cv. Marandu, lançada pela Embrapa na década de 1980, contempla mais de $50 \%$ do mercado nacional de forrageiras (ZIMMER \& EUCLIDES FILHO, 1997), sendo uma das espécies mais utilizadas na integração entre a agricultura e a pecuária no Brasil.

Na integração, a espécie forrageira é dessecada para o plantio direto da soja. Todavia, temse observado nessas áreas que a forrageira se torna a principal espécie daninha que compete com a soja, devido ao banco de sementes formado pela pastagem anterior. Para que seja estabelecido um programa racional de manejo de plantas daninhas, informações sobre a ecologia dessas plantas são de grande importância, principalmente estudos que determinem o potencial competitivo de cada espécie daninha em relação a cada cultura (BLANCO, 1993).

Diversos trabalhos mostram que diferentes espécies daninhas apresentam capacidades distintas de competição em relação à cultura da soja (CHEMALE \& FLECK, 1982; PITELLI et al., 1983; VOLL et al., 2002; FLECK et al., 2004; RIZZARDI et al., 2004). Estudos sobre competição relativa de espécies daninhas em relação a cultivares de soja mostraram que espécies como $\boldsymbol{B}$. plantaginea, Ipomoea grandifolia, Euphorbia heterophylla e Senna obtusifolia reduziram a produtividade da soja de forma distinta, com decréscimos de 19, 25, 32 e 47\%, respectivamente (VOLL et al., 2002).

A época de emergência das plantas daninhas também tem grande contribuição na interação competitiva entre espécies. Observou-se que 96\% das variações na queda de rendimento da soja foram explicadas pela variação na época de emergência das plantas daninhas; apenas 13\% das diferenças de produtividade foram explicadas pela variação na densidade destas plantas (KROPFF \& LOTZ, 1992). A época de emergência das plantas daninhas, em relação à cultura da soja, influenciou a intensidade de redução de biomassa da cultura (RIZZARDI et al., 2004). O atraso na emergência da soja em relação a picão-preto e guanxuma aumenta os efeitos negativos dessas espécies sobre a cultura, os quais são potencializados pelo incremento da densidade, principalmente para picão-preto (FLECK et al., 2004).

Neste trabalho objetivou-se quantificar os efeitos da interferência de $\boldsymbol{B}$. brizantha, emergida em diferentes épocas em relação à cultura da soja, sobre caracteres produtivos, acúmulo e distribuição de biomassa seca de ambas as espécies.

\section{MATERIAL E MÉTODOS}

O experimento foi conduzido em casa de vegetação, no período de novembro de 2003 a abril de 2004, sendo as plantas cultivadas em vasos contendo 6,0L de substrato (mistura de Argissolo Vermelho-Amarelo câmbico, fase terraço, e areia, na proporção de 2,5:1, respectivamente, acrescida de 250mg de superfosfato simples vaso ${ }^{-1}$ ). Durante o desenvolvimento do experimento, foram feitas adubações periódicas de cobertura, com solução contendo $\mathrm{N}$ e $\mathrm{K}_{2} \mathrm{O}$ acrescida de macronutrientes secundários e micronutrientes. Cada vaso representou uma unidade experimental contendo três plantas de B. brizantha cv. MG5 e uma de soja cv. UFV 16. As sementes de soja, semeadas em 16/12/2003, foram inoculadas com as estirpes SEMIA 587 e SEMIA 5019 de Bradyrhizobium japonicum antes da semeadura.

O delineamento experimental adotado foi inteiramente casualizado, com oito tratamentos e quatro repetições. Os tratamentos foram constituídos por sete épocas de emergência de $\boldsymbol{B}$. brizantha em relação à soja $(-21,-14,-7,0,7,14$ e 21 dias da emergência da soja) e uma testemunha com apenas soja.

As sementes de $\boldsymbol{B}$. brizantha foram semeadas diretamente nos vasos, sendo o primeiro tratamento (B. brizantha emergida 21 dias antes da emergência da soja) semeado em $25 / 11 / 2003$, e assim por diante, a intervalos de sete dias, de forma que a emergência coincidisse com os períodos predeterminados, sendo posteriormente desbastadas para três plantas.

Foram realizadas avaliações em dois estádios de desenvolvimento da soja: quando as plantas de soja atingiram o estádio fenológico de pleno florescimento (estádio R2) e na maturação plena das plantas de soja (estádio R8), segundo escala de FEHR et al. (1971).

Na primeira avaliação, foram determinados a área foliar, o número de folhas trifolioladas e de nós 
e a biomassa seca da raiz, da haste, das folhas e dos nódulos das plantas de soja. Em B. brizantha, foram avaliados o número de colmos, a área foliar e a biomassa seca das raízes, dos colmos e das folhas. Na segunda avaliação, foram determinados a biomassa seca total da parte aérea das plantas de $\boldsymbol{B}$. brizantha e o número de colmos. Nas plantas de soja foram avaliados a produção de grãos planta ${ }^{-1}$ e o número de vagens planta $^{-1}$ e de sementes vagem ${ }^{-1}$. Na obtenção da biomassa seca das plantas, utilizou-se estufa de circulação forçada de ar a $70^{\circ} \mathrm{C} \pm 2^{\circ} \mathrm{C}$, onde o material vegetal permaneceu até atingir peso constante.

Os dados obtidos foram submetidos à análise de variância, sendo as estimativas dos parâmetros da regressão do modelo obtidas utilizandose o programa SIGMAPLOT. Foram adotados três modelos sigmoidais: $\hat{\mathrm{Y}}=\mathrm{a} /\left(1+\exp \left(-\left(\mathrm{x}-\mathrm{x}_{0}\right) / \mathrm{b}\right)\right)$, $\hat{\mathrm{Y}}=\mathrm{Y}_{0}+\mathrm{a} /\left(1+\exp \left(-\left(\mathrm{x}-\mathrm{x}_{0}\right) / \mathrm{b}\right)\right) \mathrm{e} \mathrm{Y}=\mathrm{a}^{*} \exp (-\exp (-(\mathrm{x}-$ $\mathrm{x}_{0}$ )/b)). Para comparar o tratamento da soja em monocultivo com as médias dos demais tratamentos foi utilizado o teste de Dunnett a 5\% de probabilidade.

\section{RESULTADOS E DISCUSSÃO}

Todas as características da soja e de $\boldsymbol{B}$. brizantha foram influenciadas pelas épocas de emergência da forrageira em relação à soja. A partir da emergência da forrageira simultaneamente a da soja, observou-se maior alocação de biomassa para a haste, seguida pelas folhas e raízes da soja (Figura 1A). Todavia, verificou-se partição de biomassa semelhante quando $\boldsymbol{B}$. brizantha emergiu a -21 e -14 dias da emergência da soja.

Considerando que, no início do desenvolvimento, as folhas da soja apresentam maior participação no acúmulo de massa seca, havendo

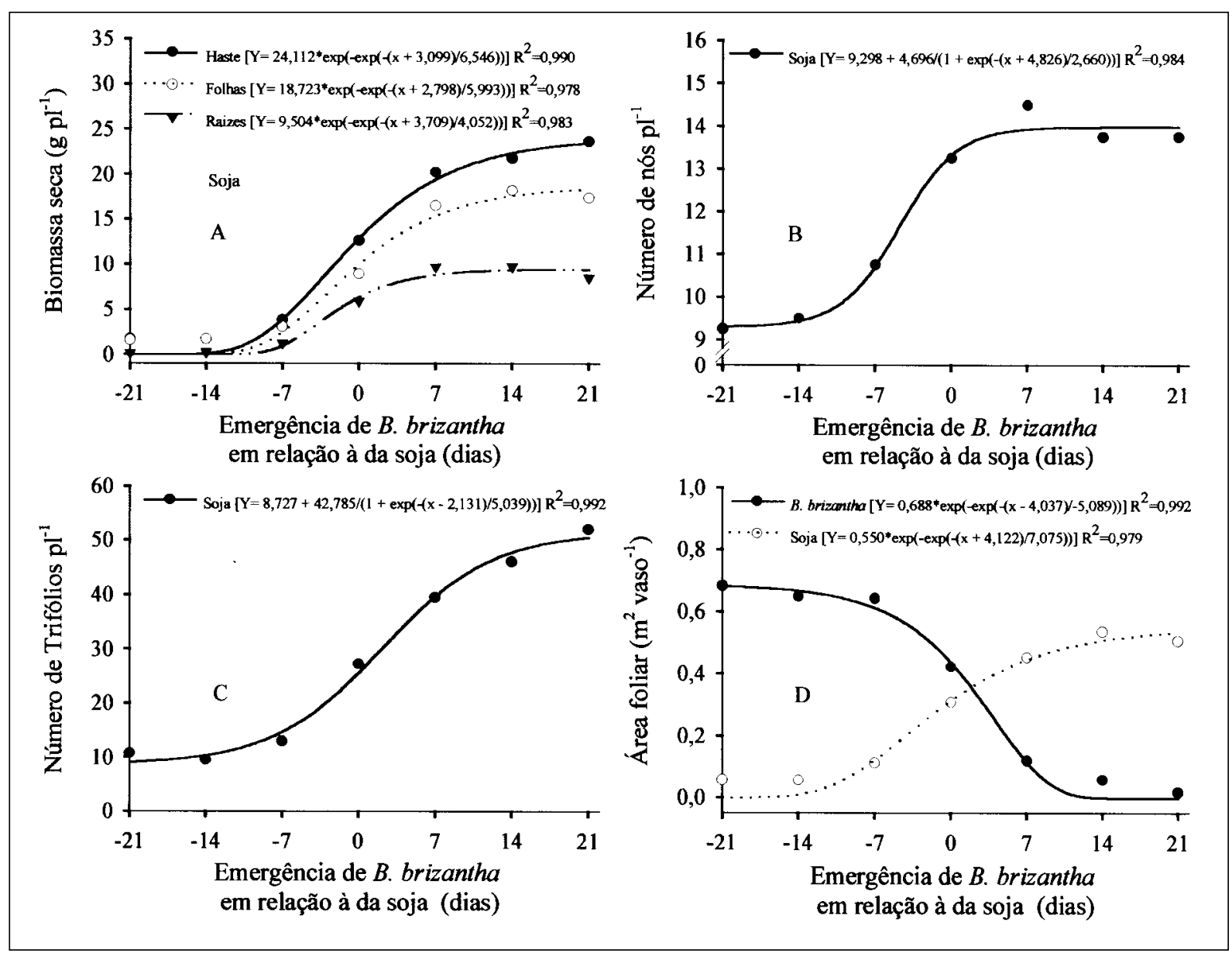

Figura 1 - Biomassa seca de folhas, haste e raízes (A), número de nós (B) e de trifólios (C) da soja, área foliar (D) da soja e B. brizantha, avaliados no estádio R2 da soja, em função de diferentes épocas de emergência de $\boldsymbol{B}$. brizantha em relação à da soja. ViçosaMG, 2004. 
posteriormente inversão na representatividade das folhas por caules, seguida por estruturas reprodutivas (MELGES et al., 1989; PEDRINHO JÚNIOR et al., 2004), os resultados evidenciaram atraso no desenvolvimento da soja em virtude da competição mais acirrada exercida por $\boldsymbol{B}$. brizantha quando emergida anteriormente à soja, o que é comprovado pelo menor número de nós (Figura 1B) e de trifólios (Figura 1C) e pela reduzida área foliar (Figura 1D) das plantas nesses tratamentos. Experimentos demonstraram que a época de emergência das plantas daninhas Ipomoea ramosissima e Euphorbia heterophylla, em relação à emergência da soja, afetou o ganho de biomassa da cultura. A emergência das plantas daninhas quatro dias antes daquela da soja, ocasionou queda de biomassa de $42,4 \%$, ao passo que na emergência simultânea a da soja as perdas foram de 22,7\% (RIZZARDI et al., 2004).

O menor desenvolvimento da soja (redução de 42,78 trifólios) causado pela interferência da $\boldsymbol{B}$. brizantha fica evidente observando-se o parâmetro "a” da equação referente ao número de folhas trifolioladas, o qual representa a amplitude entre o limite superior e o inferior dos tratamentos (Figura 1C).

Observando a figura $1 \mathrm{D}$, verifica-se que as espécies apresentaram área foliar muito próximas quando emergiram simultaneamente. Considerando que a proporção entre $\boldsymbol{B}$. brizantha e soja foi de 3:1, a leguminosa se mostrou boa competidora. Quando a forrageira emergiu sete dias após a soja, teve seu desenvolvimento suprimido pelo da leguminosa. FLECK et al. (2004) observaram que, à medida que atrasou a época de emergência das plantas daninhas em relação a da soja, reduziram-se os valores das variáveis das plantas daninhas, como biomassa seca, altura de planta e cobertura do solo.

Na comparação entre as características obtidas com a soja em monocultivo e aquelas dos demais tratamentos, observou-se que a biomassa seca de folhas, haste e raízes da soja (Figura 1A) não foi alterada quando $\boldsymbol{B}$. brizantha emergiu a partir de sete dias após a soja. Todavia, a área foliar (Figura 1D) e o número de folhas trifolioladas (Figura 1C) foram mais sensíveis à interferência, sendo necessário que $\boldsymbol{B}$. brizantha emergisse pelo menos 14 dias após a soja para que essas características não fossem comprometidas. O número de nós (Figura 1B) mostrou-se menos sensível à competição, bastando as espécies emergirem simultaneamente para que esta característica não fosse afetada.

A biomassa seca dos nódulos da soja foi severamente reduzida quando $\boldsymbol{B}$. brizantha emergiu antes ou simultaneamente à soja (Figura 2A). Segundo
MELGES et al. (1989), plantas sombreadas apresentam menor taxa assimilatória líquida, resultando em menor suprimento de fotoassimilados, tanto para crescimento das plantas como para formação de nódulos. Quando a forrageira emergiu sete dias após a soja, a biomassa de nódulos foi semelhante à da testemunha.

Quanto à distribuição de biomassa seca entre os órgãos de $\boldsymbol{B}$. brizantha, pode-se observar (Figura 2B) que as raízes apresentaram maior contribuição na biomassa seca da planta em comparação à soja, o que é favorável ao processo de integração agricultura-pecuária. Trabalhos mostram que raízes de soja ultrapassam $0,45 \mathrm{~m}$ de profundidade quando em seqüência à pastagem, sugerindo que o sistema radicular remanescente da braquiária favorece o maior crescimento do sistema radicular da soja (SALTON et al.,1999).

O número de colmos de $\boldsymbol{B}$. brizantha, que reflete o perfilhamento da forrageira, foi reduzido quando a emergência da forrageira ocorreu após a da soja (Figura 2C). DIAS-FILHO (2000) demonstrou que há redução no perfilhamento de $\boldsymbol{B}$. brizantha quando esta se desenvolve sob sombreamento, comparada a pleno sol.

Por ocasião da colheita da soja (115 DAE), verificou-se que o número de colmos de $\boldsymbol{B}$. brizantha (Figura 3A) aumentou em todos os tratamentos no que se refere à avaliação efetuada aos 60 DAE. Comparando as equações de regressão das duas avaliações (Figuras 2C e 3A), observa-se, pelo parâmetro “a”, que a amplitude entre os tratamentos extremos aumentou consideravelmente, verificandose 32,8 e 57,06 colmos na primeira e segunda avaliações, respectivamente, evidenciando assim a supressão da soja por B. brizantha, e vice-versa, no decorrer do ciclo.

O acúmulo final de biomassa seca da parte aérea de $\boldsymbol{B}$. brizantha foi drasticamente reduzido quando esta emergiu entre zero e sete dias a partir da emergência da soja (Figura 2B), evidenciando a capacidade da soja na ocupação do espaço a partir desse período.

O número de sementes por vagem apresentou valor de $\mathrm{x}_{0}$ de 9,16 dias (Figura 3C), ou seja, para reduzir $50 \%$ do número de sementes por vagem, $\boldsymbol{B}$. brizantha teria que emergir 9,16 dias antes da soja. Contudo, para produção e número de vagens, a redução de $50 \%$ ocorreu mesmo quando a forrageira emergiu cerca de três dias após a soja, indicando que o número de sementes por vagem foi a característica da soja, avaliada na colheita, menos influenciada pela competição com $\boldsymbol{B}$. brizantha, não diferindo da soja 


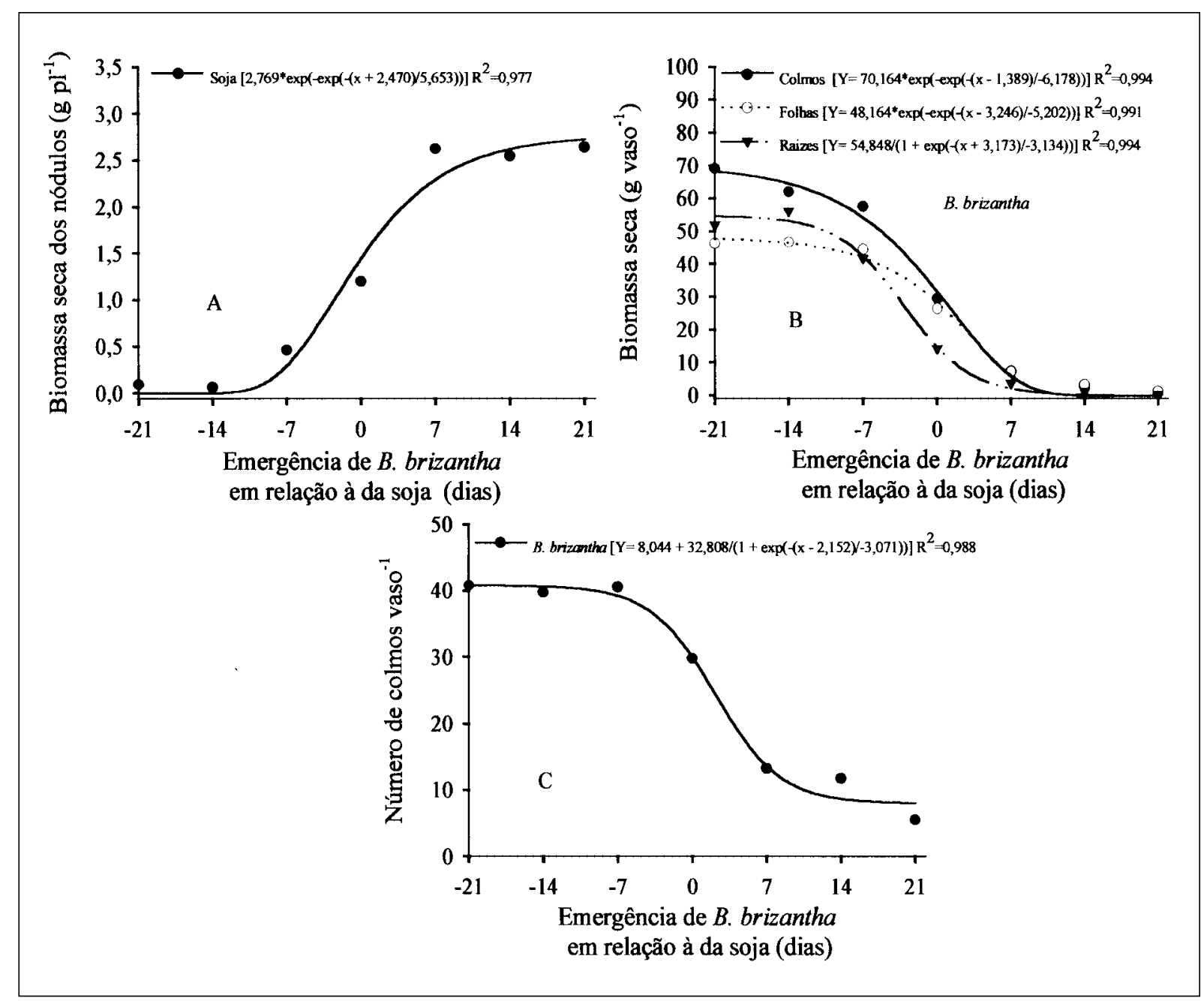

Figura 2 - Biomassa seca dos nódulos de soja (A), biomassa seca de folhas, colmos e raízes (B) e número de colmos (C) de B. brizantha, avaliados no estádio R2 da soja, em função de diferentes épocas de emergência de B. brizantha em relação à da soja. Viçosa-MG, 2004.

em monocultivo a partir da emergência de $\boldsymbol{B}$. brizantha sete dias antes da soja.

O parâmetro “a” da equação referente ao número de vagens (Figura 3D) revela diferença de 129,7 vagens entre as plantas dos tratamentos com maior e menor competição, indicando o número de vagens como ótimo indicador para evidenciar o efeito da competição. Somente o tratamento onde $\boldsymbol{B}$. brizantha emergiu 21 dias após a soja não diferiu da soja em monocultivo. Segundo JIANG \& EGLI (1993), o sombreamento reduz o número de vagens por planta, sendo essa redução atribuída ao aumento da abscisão de flores e vagens e ao menor número de flores produzidas por planta. De acordo com esse autor, o sombreamento reduz também o número de nós da haste principal, assim como o de flores por nó.

Quanto ao efeito da época de emergência de B. brizantha sobre a produção de grãos por planta da soja (Figura 3E), verificou-se incremento acentuado a partir da emergência da forrageira sete dias após a soja, ou seja, quando esta começa a obter vantagem em relação à $\boldsymbol{B}$. brizantha. Nenhum tratamento avaliado igualou-se ao da soja em monocultivo quanto à produção de grãos por planta, verificando-se redução de rendimento de aproximadamente 97, 96, 91, 80, 34, 27 e 15\% quando $\boldsymbol{B}$. brizantha emergiu aos -21, -14, -7, 0, 7, 14 e 21 dias em relação à soja, respectivamente, sendo o acúmulo de biomassa seca da parte aérea da forrageira por ocasião da colheita de 275, 279, 267, 202, 79, 46 e 23 gramas por vaso, nesses respectivos tratamentos.

\section{CONCLUSÕES}

As características morfológicas da soja apresentaram suscetibilidade diferenciada devido 


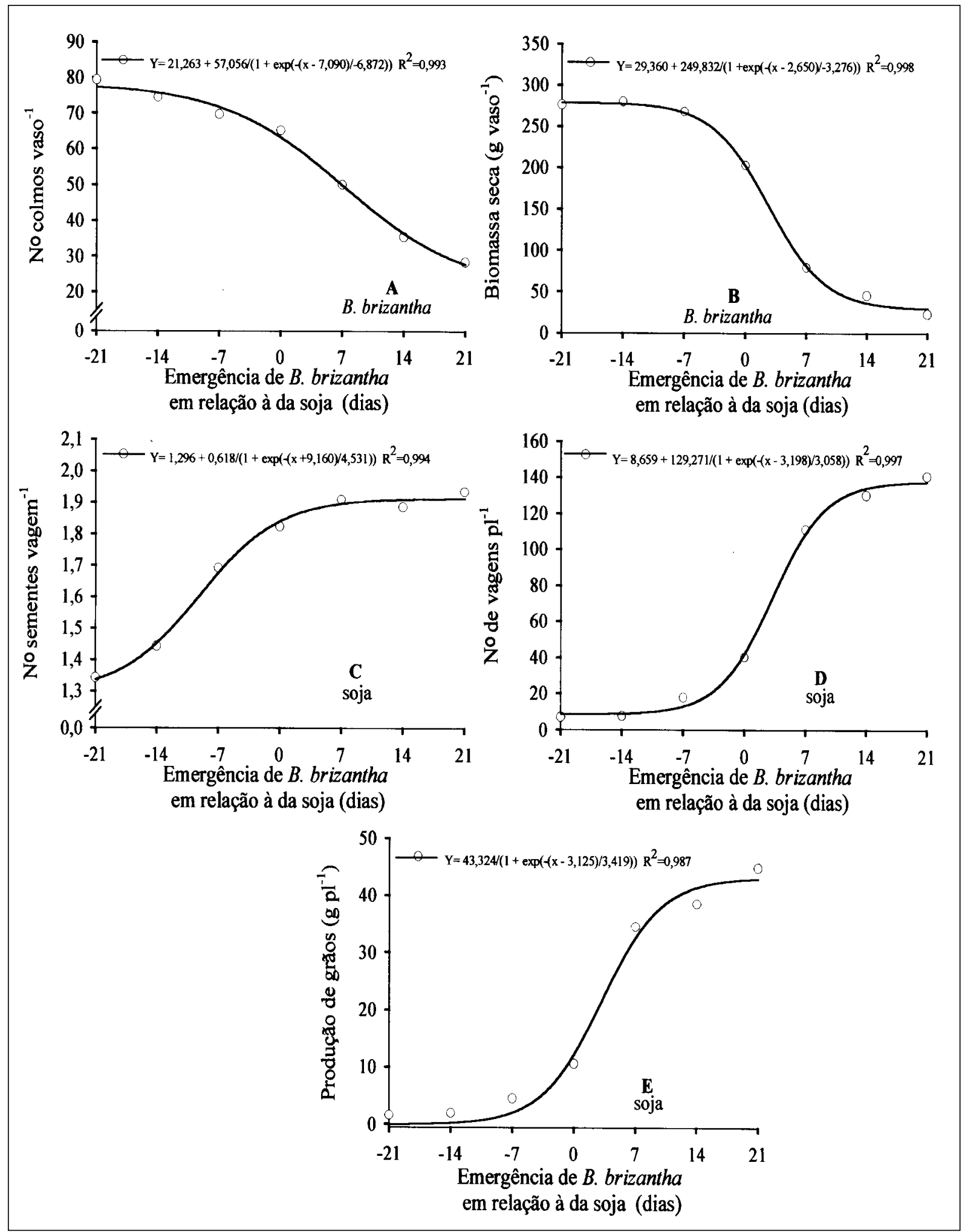

Figura 3 - Número de colmos (A) e biomassa seca da parte aérea (B) de B. brizantha; número de sementes por vagem (C), número de vagens por planta (D) e produção de grãos de soja (E), avaliados no estádio R8 da soja, em função de diferentes épocas de emergência de $\boldsymbol{B}$. brizantha em relação à da soja. Viçosa-MG, 2004.

Ciência Rural, v.35, n.4, jul-ago, 2005. 
à interferência de $\boldsymbol{B}$. brizantha. O número de folhas trifolioladas e a área foliar foram as características da soja mais afetadas pela forrageira. As raízes de $\boldsymbol{B}$. brizantha apresentaram maior contribuição na biomassa seca total da planta em comparação a soja. A produção de grãos de soja aumentou com o atraso na emergência de $\boldsymbol{B}$. brizantha. Em áreas de plantio de soja infestadas com $\boldsymbol{B}$. brizantha, o controle da forrageira deve ser efetuado por, no mínimo, 21 dias após a emergência da soja.

\section{REFERÊNCIAS}

BLANCO, H.G. Manejo de plantas daninhas: uma abordagem ecológica. In: SIMPÓSIO DE AGRICULTURA ECOLÓGICA, 1., Campinas, 1993. Anais... Campinas : IAC, 1993. p.67-76.

CHEMALE, V.M.; FLECK, N.G. Avaliação de cultivares de soja (Glycine max (L.) Merrill) em competição com Euphorbia heterophylla L. sob três densidades e dois períodos de ocorrência. Planta Daninha, v.2, p.36-45, 1982.

DIAS-FILHO, M.B. Growth and biomass allocation of the $\mathrm{C}_{4}$ grasses Brachiaria brizantha and $B$. humidicola under shade. Pesq Agropec Bras, v.35, n.12, p.2335-2341, 2000.

FEHR, W.R. et al. Stage of development descriptions for soybeans, Glycine $\max (\mathrm{L}$.) Merrill. Crop Sci, v.11, p.929931, 1971.

JIANG, H.; EGLI, D.B. Shade induced changes in flower and pod number and flower and fruit abscission in soybean. Agron J, v.85, p.221-225, 1993.

FLECK, N.G. et al. Interferência de picão-preto e guanxuma com a soja: efeitos da densidade de plantas e época relativa de emergência. Ciência Rural, v.34, n.1, p.41-48, 2004.
KICHEL, A.N. et al. Produção de bovinos de corte com a integração agricultura $x$ pecuária. In: SIMPÓSIO DE FORRAGICULTURA E PASTAGENS: TEMAS EM EVIDÊNCIAS, 1., 2000, Lavras. Anais... Lavras : UFLA, 2000. p.51-68

KROPFF, M.J.; LOTZ, L.A.P. Optmization of weed management systems: the role of ecological models of interplant competition. Weed Technol, v.6, p.462-470, 1992.

MELGES, E. et al. Efeito da densidade do fluxo radiante sobre a nodulação da soja. Pesq Agropec Bras, v.24, n.9, p.10931102, 1989

PEDRINHO JÚNIOR, A.F.F. et al. Acúmulo de massa seca e macronutrientes por plantas de Glycine max e Richardia brasiliensis. Planta Daninha, v.22, n.1, p.53-61, 2004

PITELLI, R.A. et al. Estudo de competição inter e intraespecífica envolvendo Glycine max (L.) Merrill e Cyperus rotundus (L.), em condições de casa de vegetação. Planta Daninha, v.6, n.2, p.129-137, 1983.

RIZZARDI, M.A. et al. Interferência de populações de Euphorbia heterophylla e Ipomoea ramosissima isoladas ou em misturas sobre a cultura da soja. Planta Daninha, v.22, n.1, p.29-34, 2004

SALTON, J.C. et al. Alterações em atributos físicos do solo decorrentes da rotação soja-pastagem, no sistema plantio direto. Dourados : EMBRAPA, 1999. 5p. (Comunicado Técnico da Embrapa, n.10)

VOLL, E. et al. Competição relativa de espécies de plantas daninhas com dois cultivares de soja. Planta Daninha, v.20, n.1, p.17-24, 2002.

ZIMMER, A.H.; EUCLIDES FILHO, K. As pastagens e a pecuária de corte brasileira. In: SIMPÓSIO INTERNACIONAL SOBRE PRODUÇÃO ANIMAL EM PASTEJO, 1997, Viçosa. Anais... Viçosa : José Alberto Gomide, 1997. p.349-379. 